\title{
Into the next decade
}

As the Journal of Micropalaeontology enters its second decade, the editorial board has taken the opportunity to introduce some changes in its format. You may have already noticed the different layout of the title pages and the way in which text wraps around diagrams; we have also changed the font and font size, and are using more bold lettering in the systematics sections and explanation of plates. We hope that these changes will make the Journal easier to read. We also considered publication on matt paper, and thanks to the helpfulness of the printer were able to compare plates printed on different paper; however the editorial board was unanimous in deciding to keep with glossy paper because detail was clearly lost when plates were printed on matt.

The end of one decade and the start of a new one is always a time for reflection. The Journal is a valuable vehicle for the publication of systematic work, and this will remain its primary role. However, the editors would like to see the submission of more of the "ideas" type of paper. Some thoughts on this are offered here. The first of what is hoped to be a series, "Essays in Micropalaeontology", is published in this part. The format is intended for short critiques, opinions, or discussion of topics which are of interest to a wide audience. They may deal with a particular group of micro-organisms, but the content should be of general interest to most micropalaeontologists. John Haynes has opened the series with a critique of the ecophenotypic concept as applied to foraminifera. We are all aware of the way this idea has come to dominate much systemmatic work today, reviving the old conflict between "lumpers" and "splitters", and even hinting at a conflict between Darwinism and Lamarckism. The interesting feature of John's contribution is that it deals with intensely studied living species (or a single species if they really are ecophenotypic), rather than fossils for which we may be excused due to the lack of any possibility of proof. It is a truism that good systematics is at the root of good biostratigraphy and palaeoecology, so it is important to understand whether the variation we are dealing with is genetic or ecophenotypic in character.

Two further papers in this part are critical of other conventional approaches to micropalaeontological studies. Huw Griffiths and J. Evans suggest an alternative to the usual "uniformitarian" approach to palaeoenvironmental analysis, with regard to freshwater ostracods. They point out the potential flaws in the basic assumption that identicality of morphology reflects ecological identicality, or that past environments have analogues in the Recent. Chris Paul shows how misleading standard counts and percentages can be, and recommends the use of absolute numbers in palaeoecological analyses. This in turn may present problems due to the type of material being studied. The paper deals with Milankovitch cycles, which is one area where micropalaeontologists are active; there are more papers on this theme in the pipeline for future volumes.
However, many current areas of activity and intellectual thought are poorly represented in micropalaeontological papers. For example, whether or not we agree with the techniques, cladistic systematics seems to have largely passed us by. As another example, many Society members are applied biostratigraphers, yet how often are the principles of sequence stratigraphy dealt with? This is a field where accurate age dating is essential for the correct interpretation of basin evolution, but should our contribution be this limited? Many micropalaeontologists apply these ideas to their work, but the fact remains that much micropalaeontological work comes across as dull and routine compared with macropalaeontology. Undoubtedly some workers consider that micropalaeontological journals are just for systematics, and that other journals are more appropriate for more general work aimed at a wider audience. The editor hopes that in future such papers will be submitted to the Journal of Micropalaeontology.

We rarely publish review papers because few people are prepared to write them on spec. They need to cover fairly broad topics intended to convey information and ideas to the interested non-specialist. We would like to encourage the submission of such papers, but suggest that authors contact the editor first with a detailed resumé.

Finally, the "Micropalaeontology Notebook" is now firmly established, and the three included in this part of the Journal show the range of uses to which the format can be put, including short systematic notes, techniques, and reports of new occurences.

So with these thoughts in mind, we can perhaps look forward to the next decade with great expectations. However, how about a few statistics on the first ten years? Many readers complain, lightheartedly I am sure, that the Journal is dominated by ostracod papers. Well, perhaps they are correct up to a point. We will be publishing a cumulative index for Volumes 1-10 in December, which has been compiled by Lesley Shepherd. More papers have been published on ostracods than any other group - but only just! They account for 72 papers, closely followed by foraminifera at 71 and, surprisingly palynomorphs at 63 . The conodonts only manage 8 papers while calcareous algae, testate amoebae, Chitinozoa, and Muellerisphaerids only manage 1 each. So this gives us some indication for areas for potential research projects.

As a final comment, I am often asked about the waiting time for publication. This is not an easy question to answer, because so much depends upon the circumstances of individual papers; however, as can be seen in the present volume this can range from 7 months to two years. As a last piece of information, we have brought in a new editing system whereby members of the editorial board are now responsible for the total editing of papers of particular groups of microfossils, although manuscripts should still be sent to the editor.

\section{Mike Keen, Editor}

